\title{
Correction to: Human infection with Avian Influenza A virus in Nepal: requisite for timely management and preparedness
}

Krishna Prasad Acharya ${ }^{1} \cdot$ Narayan Acharya $^{2} \cdot$ Sarita Phuyal $^{3}$. Supram Hosuru Subramanya ${ }^{4}$

Published online: 27 May 2020

(C) Indian Virological Society 2020

Correction to: VirusDis.

https://doi.org/10.1007/s13337-020-00593-z

In the original publication of the article, the article title was published incorrectly. The correct title is given below:
"Human infection with Avian Influenza A virus in Nepal: requisite for timely management and preparedness" The original article has been corrected.

The original article can be found online at https:// doi.org/10.1007/s13337-020-00593-z.

Krishna Prasad Acharya

krishna.acharya@nepal.gov.np

1 Animal Quarantine Office (AQO),

Budhanilakantha, Kathmandu, Nepal

2 The Institute of Environmental and Human Health, Texas

Tech University, Lubbock, USA

3 Central Referral Veterinary Hospital,

Tripureshwar, Kathmandu, Nepal

4 Manipal College of Medical Sciences, Pokhara, Nepal 